\title{
Mechanical Performances of Pressure Arch in Thick Bedrock during Shallow Coal Mining
}

\author{
Shuren Wang $\mathbb{D}^{1,2}$ Xiaogang $\mathrm{Wu}^{1}{ }^{1}$ Yanhai Zhao, ${ }^{1}$ and Paul Hagan $\mathbb{D}^{2}$ \\ ${ }^{1}$ International Joint Research Laboratory of Henan Province for Underground Space Development and Disaster Prevention, \\ Henan Polytechnic University, Jiaozuo 454003, China \\ ${ }^{2}$ School of Mining Engineering, University of New South Wales, Sydney, NSW 2052, Australia
}

Correspondence should be addressed to Shuren Wang; w_sr88@163.com

Received 3 June 2018; Revised 4 August 2018; Accepted 19 August 2018; Published 1 October 2018

Academic Editor: Qingsheng Bai

Copyright (c) 2018 Shuren Wang et al. This is an open access article distributed under the Creative Commons Attribution License, which permits unrestricted use, distribution, and reproduction in any medium, provided the original work is properly cited.

Due to the periodicity of mine pressure, it can easily lead to a wide-range damage of the overburden rock under shallow coal mining conditions, and the falling of the overburden rock is usually a serious threat to the mining safety. Based on the monitoring data of mine pressure in a typical shallow coal mine in northern China, the mechanical model of the surrounding rock in the mining field was built and the identification indicators of the pressure arch after coal mining was defined. Then, the arching mechanism, the stress distribution characteristics in different positions, and the bearing capacity of the pressure arch were analysed, and the evolution characteristics of the pressure arch under shallow horizontal coal mining were verified by numerical simulation and physical experiment. Results show that there is a core-bearing zone in the pressure arch, and the width of the core zone determines the bearing capacity of the pressure arch. The evolution of the pressure arch affects the formation and development of the caving arch of the loose zone in the mining field. The conclusions obtained in the study are of important theoretical value to direct the similar engineering practice.

\section{Introduction}

During shallow coal mining with thick bedrock in western area in China, the overlying strata show the features of alternate instability, and the strong (weak) roof weighting on the working face often induces support crushing accidents. The stability of the surrounding rock is the key problem which restricts the safety mining $[1,2]$. With the working face advancing, the pressure arch in the surrounding rock can be formed and the caving zone below the pressure arch can expand gradually [3]. Determination of the forming conditions and arching characteristics of the pressure arch in the mining field and analysing the nonuniform weighting mechanism on the working face during shallow coal mining with thick bedrock are the urgent problems to be solved.

As we all know, the pressure arch widely exists in the surrounding rock after the coal mining and the pressure arch helps in keeping the roof stability during the coal mining. Ren and Qi found that the load of hanging strata in the mining field can be transmitted to the surrounding rock in the far field by the pressure arch, and the size, the inner and outer boundary of the pressure arch, affects the load transferring laws of the roof strata [4]. Due to the fact that the pressure arch is a macro bearing structure in the surrounding rock and different morphologies of the pressure arch have different bearing capacities, some mechanics index can be used to determine the bearing capacity of the pressure arch. The formation of the caving zone is formed by the instability of the pressure arch; the weight of the caving zone is the load source of supporting equipment on the working face. Therefore, the interaction between the pressure arch and the caving zone is an important basis for the design of the support resistance.

The macroscopic pressure arch functions as a selfsupporting structure in the bedrock of the mining field, and which size affects the bearing capacity. The evolution characteristics of the pressure arch have an important influence on the scope of the caving zone and the weighting laws on the working face. Based on the strata behaviours of a typical working face in Shangwan mine in Shendong mining area 
in China, the mechanical model of the pressure arch in the surrounding rock was constructed and the identification indicators of the arching parameters were proposed in this paper. The evolution characteristics of the pressure arch and the caving zone under the thick bedrock condition were analysed and verified by the physical test of the similar materials and numerical simulation during shallow coal mining. The size of the pressure arch and the distribution characteristics of the load-bearing zone were obtained. The nonuniform weighting mechanism of the working face was revealed. The results are of great significance to the safety mining in the similar engineering practice.

\section{State of the Art}

The principal stress in the surrounding rock after coal mining has the characteristics of self-adjusting and forming a pressure arch. As a bearing structure, the pressure arch protects the stability of the mining field. The pressure arch can provide a reliable basis for determining the support resistance of the working face.

Xie et al. studied the distribution characteristics of pressure arch in deep mining by similar material test and numerical simulation. They found that there was a macroscopic pressure arch around the mining field which bore the hanging strata load, and the instability of the strata below the pressure arch caused the periodic weighting on the working face [5]. Cui et al. analysed the instability mechanism of the overburden strata being induced by the shallow coal mining. They thought that the pressure arch in the near- and far field was converged under the mining disturbance; the failure of the thick and hard rock strata led to the disappearing of the pressure arch and the instability of the overburden rock [6]. Wang et al. established the mechanical model of the pressure arch and analysed the instability mechanism of the pressure arch in the mining field with different dip angles. They found that with the increase of coal seam dig angle, the failure mode of the pressure arch was gradually from compression, shear to tensile failure, and the local damage could cause the overall structural instability finally [7]. The above studies show that the instability of the pressure arch can lead to the formation of the caving zone. However, during shallow coal mining, the forming conditions and evolution characteristics of the pressure arch in the overburden rock with the thick bedrock are still lack of reports.

Under the shallow coal mining, the instability of the overburden caving zone often brings about a sharp increase in support resistance and which is an important threat to the safety mining. Based on the laws of mining pressure observation in the fully mechanized working face, Ju and $\mathrm{Xu}$ [8] and Huang et al. [9] revealed the alternated regularity of the interval and strength of weighting by using the combined mechanics models of voussoir beam and cantilever beam, and they pointed out that the premature rupture of the key strata and the step subsidence would result in the weighting of the alternated regularity of strong (weak) periodically. According to the strength and thickness of the overburden rock in Shendong mining area, Liu et al. classified the characteristics of the overburden strata in shallow coal mining and analysed the bearing characteristics and load transfer laws of the overburden strata in the caving zones [10]. Soni et al. summarized the instability characteristics of thin bedrock mining by monitoring the instability of the overlying strata during shallow coal mining in Kampudi coal mine in India [11]. Helm et al. [12] and Salmi et al. [13] studied the instability mechanism of the overburden strata under shallow coal mining in Edinburgh, UK. The instability of the overlying strata in shallow coal mining has been extensively studied. However, to consider the influences of the pressure arch bearing capacity on the range of the overlying strata is lack of report, and the interaction between the pressure arch and the caving zone still needed further study.

There are different viewpoints on the pressure arch boundary in the surrounding rock and the loosening area under the pressure arch. Through numerical simulation of the roof load distribution in the goaf by DDA software, $\mathrm{He}$ and Zhang found that the loosening area under the pressure arch could not bear the overburden pressure, the principal stress in this region was mainly horizontal stress and the vertical stress was close to zero, and the separated rocks tended to slip off [14]. Wang et al. applied the pressure arch theory to predict the caving range of the deep tunnel roof and took the zero tensile stress curves as the inner boundary of the pressure arch [15]. Kong et al. analysed the formation and evolution of the pressure arch in the surrounding rock by numerical simulation. Based on lateral and vertical stress distribution, they obtained the morphological characteristic curves and established a method of identifying the pressure arch range [16]. Overall, the loosening rocks under the pressure arch threaten the safety mining, and the support resistance is determined by the caving zone movement. So it is an urgent issue to determine the loosening area and reveal the instability mechanism of the pressure arch under shallow coal mining.

Though, there are many results of the morphology and stress distribution of the pressure arch. However, there is lack of some effective indicators to identify the size and bearing capacity of the pressure arch, and the interaction between the pressure arch and the caving zone during coal mining needs to be further studied. Therefore, this paper will focus on analysing the evolution characteristics of the pressure arch in thick bedrock during shallow horizontal coal mining, try to propose the mechanical criteria to evaluate the pressure arch size and bearing capacity, and research the interaction between the pressure arch and the caving zone during shallow coal mining by physical test and numerical simulation.

\section{Research Methods}

3.1. Engineering Background. As shown in Figure 1(a), Shangwan coal mine was located in Inner Mongolia province in northern China. Taking no. 51104 working face of $1^{-2}$ coal seam in Shangwan mine in Shendong mining area in China as the engineering background, as shown in Figure 1(b), the longwall and full thickness mining technology was adopted in the working face, and the caving method was used to manage the roof. The working face width was $301 \mathrm{~m}$, the dip angle was $0^{\circ}-5^{\circ}$, and the average depth was $115.4 \mathrm{~m}$. 


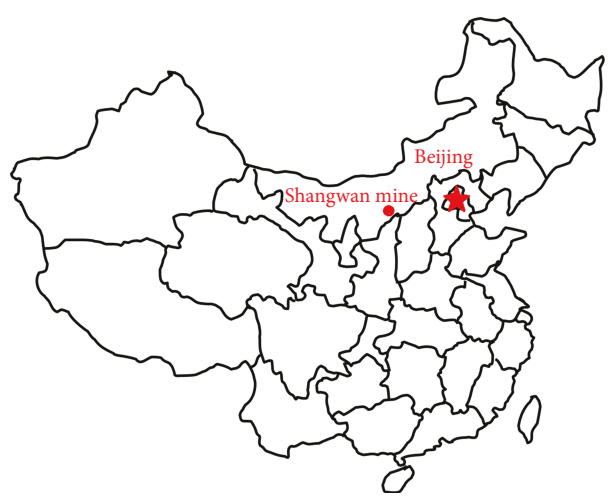

(a)

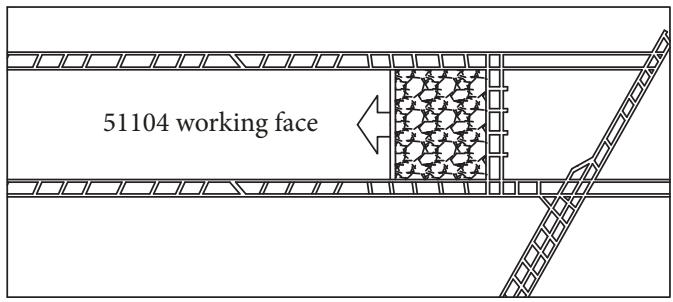

(b)

FIGURE 1: Shangwan coal mine and 51104 working face. (a) Shangwan coal mine location. (b) 51104 working face arrangement.

\begin{tabular}{|c|c|c|c|}
\hline Lithology & Formation & $\begin{array}{l}\text { Depth } \\
\text { (m) }\end{array}$ & $\begin{array}{c}\text { Thickness } \\
\text { (m) }\end{array}$ \\
\hline & Coarse sandstone & 81.4 & 9.0 \\
\hline & Fine sandstone & 82.1 & 0.7 \\
\hline & Sandy clay rock & 83.2 & 1.1 \\
\hline & Siltstone & 86.5 & 3.3 \\
\hline & Coarse sandstone & 96.0 & 9.5 \\
\hline & Sandstone & 106.4 & 10.4 \\
\hline 4 & Sandy mudstone & 108.9 & 2.5 \\
\hline & $1^{-2}$ coal seam & 115.4 & 6.5 \\
\hline & Siltstone & 130.4 & 15.0 \\
\hline
\end{tabular}

Figure 2: The roof and floor lithology closed to no. $1^{-2}$ coal seam.

The rock formation in Shendong mining area was mainly formed during the Cretaceous, Jurassic, and Quaternary periods, and among the Quaternary period was sandy soil layer; there were eleven kinds of lithology in the rock strata in this area, and the Cretaceous strata was mainly sandstone. The roof and floor lithology closed to no. $1^{-2}$ coal seam were shown in Figure 2, and the average thickness of the coal seam was $6.5 \mathrm{~m}$ [17].

As seen from Figure 3, there were 20 times weighting that occurred during the observation period, and the weighting interval varied at $9.4-32.3 \mathrm{~m}, 16.7 \mathrm{~m}$ in average. The support resistance was $5571-8975 \mathrm{kN}, 7107 \mathrm{kN}$ in average, and the rated working resistance was $8638 \mathrm{kN}$. During coal mining with the thick bedrock and thin loose layer, the strata behaviours had the periodically strong (weak) features, and the weighting appeared the alternated regularity of long (short) periodically. For part of the periodic weighting, the short interval corresponded to the strong weighting, and the normal weighting alternated with strong (weak) weighting.

3.2. Theoretical Analysis. After shallow coal mining, the load of the overburden rock was transferred to the stable surrounding rock in the mining field. As shown in Figure 4, the maximum principal stress $\sigma_{1}$ was deflected and the concentrated zone was around the mining field. The pressure arch was formed in the concentration zone of the compressive stress, of which the inner principal stress $\sigma_{1}$ surpassed the in situ stress $p_{0}$, which was

$$
\sigma_{1}>p_{0}=\gamma h
$$

where $\gamma$ was the average volume-weight of the rock mass and $h$ was the burial depth.

Outside the outer boundary of the pressure arch was the in situ stress zone, and inside the inner boundary of the pressure arch was the lower pressure zone and tension stress zone. The caving arch in unloading area of the overburden rock was the key zone to the rock control, of which the weight determined the strata behaviour and the roof stability in the mining field. The spatial morphology and movement rules changed with the evolution of the $3 \mathrm{D}$ pressure arch. To define $k$ as the arching index of the pressure arch in the surrounding rock, it could be calculated by

$$
k=\frac{\sigma_{1}-\sigma_{0}}{\sigma_{0}},
$$

where $\sigma_{1}$ was the maximum principal stress after coal mining and $\sigma_{0}$ was the in situ maximum principal stress before coal mining. For $k>0$, it was the range of the pressure arch, and the lower compressive stress zone when $-1<k<0$ and the tensile stress zone when $k<-1$. 


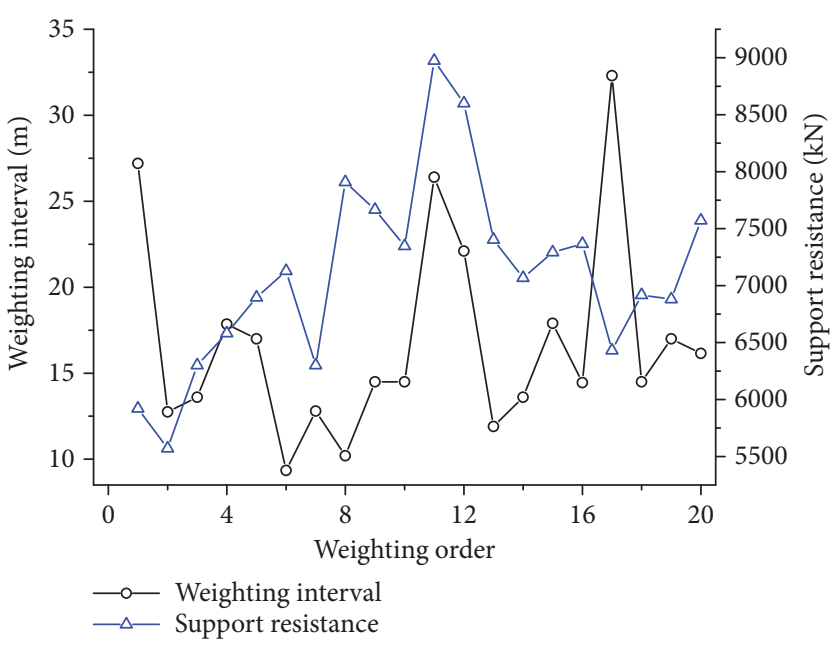

(a)

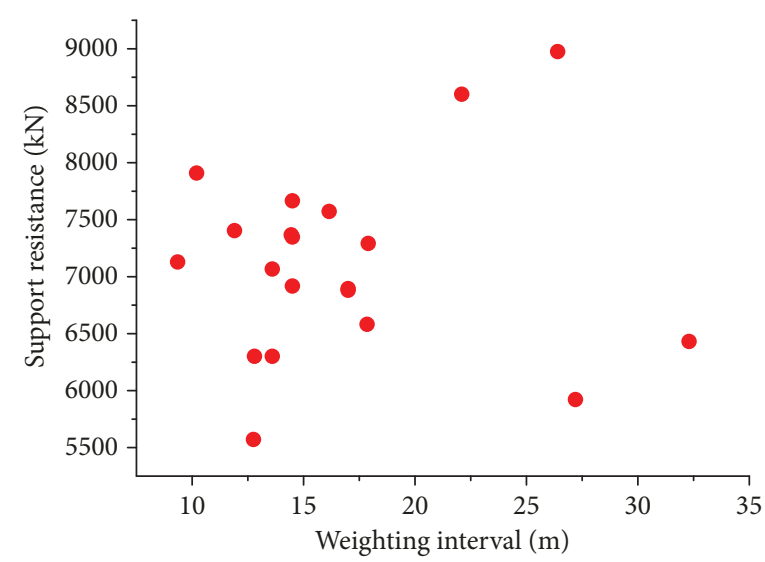

(b)

FIgURE 3: Strata behaviours of the working face. (a) Weighting order. (b) Weighting interval-support resistance.

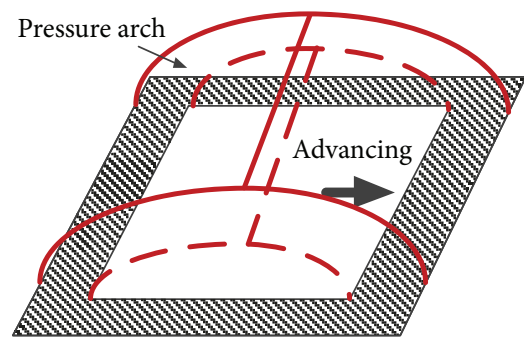

(a)

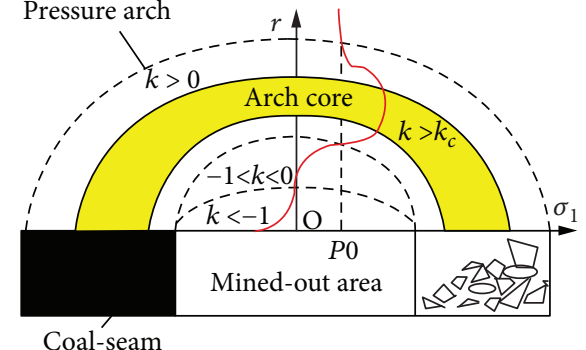

(b)

Figure 4: The pressure arch in the surrounding rock. (a) Engineering model. (b) Mechanical model.

The index $k$ reflected the stress concentration degree of the surrounding rock, and the average value of index $k$ of each position was another index to evaluate the performance of stress concentration in rock. Taking identification indicator $k_{c}$ as the average value of $k$, the indicator $k_{c}$ was the ratio of index $k$ in each rock unit to whole rock volume, which could be used to analyse the bearing capacity of the pressure arch: when $k>k_{\mathrm{c}}$, it was located in the nucleus of the pressure arch, of which the thickness of the pressure arch determined the self-bearing capacity in the surrounding rock, and when $0<k<k_{\mathrm{c}}$, it was located in the outside zone of the nucleus of the pressure arch.

3.3. Building Computational Model. Taking mining 1-2 coal seam in Shangwan mine in Shendong mining area as the engineering background, the computational model was established by FLAC ${ }^{3 \mathrm{D}}$. The thickness of the coal seam was $7 \mathrm{~m}$, the thickness of the siltstone floor was $10 \mathrm{~m}$, and the thickness of the sandstone roof was $102 \mathrm{~m}$. As shown in Figure 5, the model size was $400 \mathrm{~m}$ long, $352 \mathrm{~m}$ wide, and $137 \mathrm{~m}$ high. The load of $0.45 \mathrm{MPa}$ was applied to the top of the model substituting for the $30 \mathrm{~m}$ loose layer weight. The bottom boundary of the model was fixed, and the lateral boundaries of the model were fixed in the horizontal direction.

The position of the start mining was $150 \mathrm{~m}$ away from the left boundary, the advancing distance was $300 \mathrm{~m}$ each mining stage, and the inclined length was $240 \mathrm{~m}$. Two roadways were excavated along the $x$-axis direction $150 \mathrm{~m}$ away from both sides of the border, where width was $6 \mathrm{~m}$ and the height was $5 \mathrm{~m}$, and the excavation of the coal seam was simulated by using null model. The physical and mechanical parameters of coal and rock mass were listed in Table 1, and Mohr-Coulomb criteria were used in the numerical calculation.

3.4. Similar Materials Experiment. Taking mining $1^{-2}$ coal seam in Shangwan mine in Shendong mining area as the engineering background, the thickness of the coal seam was $7 \mathrm{~m}$, the thickness of the floor was $16 \mathrm{~m}$, and the thickness of the overlying strata was $97 \mathrm{~m}$. The self-developed similar simulation platform with combined multifunction servo control was used in the test [18], in which the size was $3.565 \mathrm{~m}$ long, $0.640 \mathrm{~m}$ wide, and $2.915 \mathrm{~m}$ high. The nonlinear load was applied independently by the lateral loading rack and the top hydraulic system to simulate different stress 


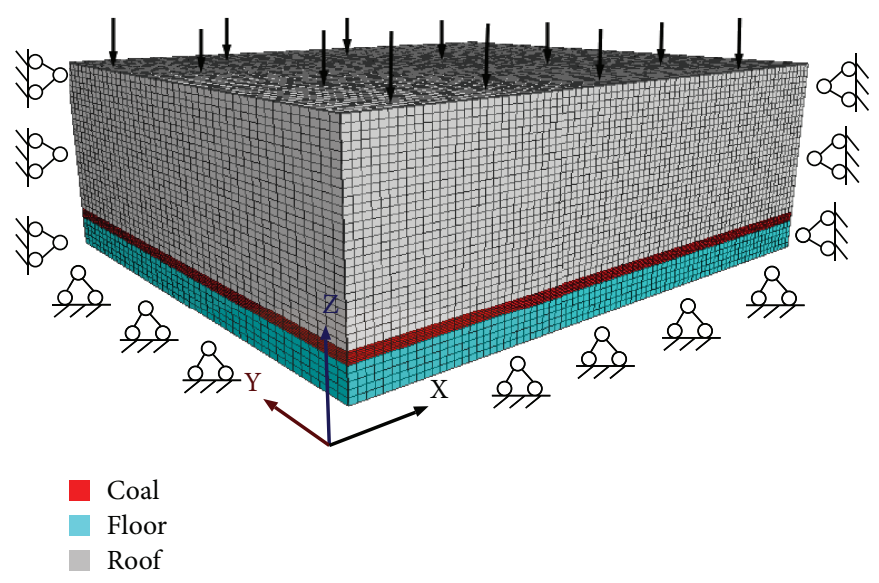

Figure 5: The computational model.

TABLE 1: Material properties of coal and roof strata.

\begin{tabular}{lcccccc}
\hline Name & $\begin{array}{c}\text { Unit weight } \\
\left.\mathrm{m}^{3}\right)\end{array}$ & $\begin{array}{c}\text { Elastic modulus } \\
(\mathrm{GPa})\end{array}$ & $\begin{array}{c}\text { Poisson's } \\
\text { ratio }\end{array}$ & $\begin{array}{c}\text { Cohesive strength } \\
(\mathrm{MPa})\end{array}$ & $\begin{array}{c}\text { Tensile strength } \\
(\mathrm{MPa})\end{array}$ & $\begin{array}{c}\text { Friction angle } \\
\left({ }^{\circ}\right)\end{array}$ \\
\hline Sandstone & 25.00 & 36.50 & 0.22 & 2.60 & 1.50 & 30 \\
Coal & 13.10 & 12.70 & 0.29 & 1.20 & 0.60 & 3 \\
Siltstone & 24.60 & 37.90 & 0.20 & 4.50 & 40 \\
\hline
\end{tabular}

conditions, and the range of the load was $0.1-100 \mathrm{kN}$. The external load was applied on the model top substituting the $40 \mathrm{~m}$ loose layer above the overlying strata, and the lateral pressure coefficient was set as 1.5 which was simulated by the lateral loading rack.

According to the similar criteria and test requirements, the geometric similarity ratio was $C_{L}=1: 100$, the time similarity ratio was $C_{t}=1: 10$, the density similarity ratio was $C_{\gamma}=1: 1.56$, and the intensity and stress similarity ratio was $C_{\sigma}=1: 156$. The model size was $275 \mathrm{~cm}$ long, $30 \mathrm{~cm}$ wide, and $120 \mathrm{~cm}$ high. The position of the start mining was $50 \mathrm{~cm}$ away from the left boundary, and the advancing distance was $6 \mathrm{~cm}$ each mining stage, $180 \mathrm{~cm}$ in total. According to the composition of similar materials, sand was selected as aggregate, gypsum as the main cementitious material, lime as an auxiliary cementitious material, borax as a retarder, and mica powder as weak plane among the strata.

The fine-grained river sand with particle size less than $0.05 \mathrm{~mm}$ was chosen as aggregate in the model experiment, gypsum was used as the main cementing material, and calcium carbonate was used as the auxiliary cementing material. To ensure the reliability of material ratio in similar simulation test, according to the proportion number 337, 455, 573 , and 673 , a small amount of river sand, calcium carbonate, and gypsum was used to make cylindrical specimens where the size was $50 \mathrm{~mm} \times 100 \mathrm{~mm}$. The uniaxial compressive test of the specimen was carried out on the servo pressure tester as shown in Figure 6. Taking the specimen of proportion number 337 as an example, the compression specimen was damaged after 83 seconds of loading, the peak strength of the specimen was $0.48 \mathrm{MPa}$.
As shown in Figure 7, there were three stress monitoring lines being set in the model $10 \mathrm{~cm}, 45 \mathrm{~cm}$, and $80 \mathrm{~cm}$ away above the top of the coal seam; the monitoring and acquisition system of stress data was mainly completed by the computer. The horizontal distance among the sensors was $10 \mathrm{~cm}$. The unit strain gauge was made of $3 \mathrm{~cm} \times 3 \mathrm{~cm} \times 3 \mathrm{~cm}$ polyurethane cube, on the three sides of the cube diagonally adjacent, three 45-degree strain flowers were pasted, and the vertical strain gauges were pasted along the horizontal and vertical directions on other surfaces. The specification of strain flower is BX120-3CA (sensitive gate size is $3 \mathrm{~mm} \times 2 \mathrm{~mm}$ ). The monitoring of principal stress in the model was achieved through the main direction strain sensor, and TST-3822 strain gauge analysis system was used to monitor the principal stress of the similar materials in the model. CTS-622-type total station was used to measure the space coordinates of the measured points to obtain the displacements of the overlying strata. The similar material ratio of the model was shown in Table 2, in which the first digital of the proportion number represented the ratio of sand and cementitious material, and the second and third digital represented the ratio of two cementitious materials.

\section{Results and Discussion}

4.1. Arching Characteristics of the Principal Stress. Choosing the middle position of the working face as the research object, the cross section was selected at $y=176 \mathrm{~m}$, and the vector field of the principal stress distribution was shown in Figure 8. The maximum principal stress in the mining field was the vertical direction, and the principal stress in the 


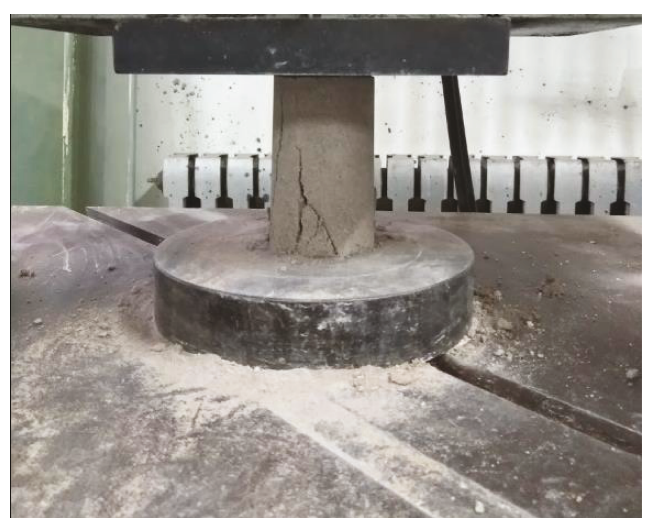

(a)

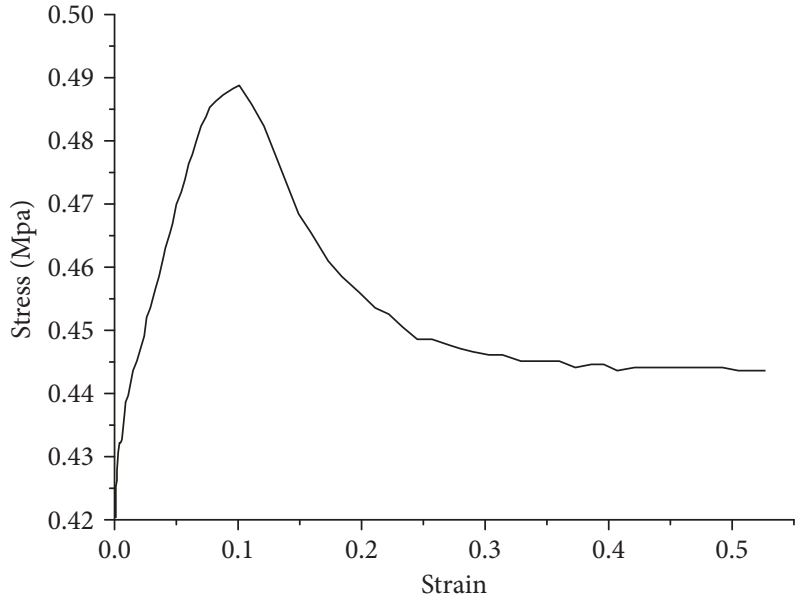

(b)

Figure 6: Mechanical tests of similar material. (a) Test specimen. (b) Stress-strain curve.

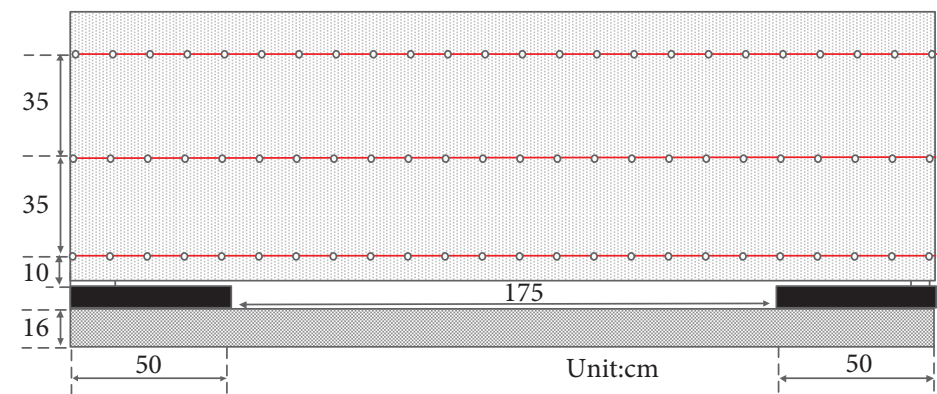

-o- Stress monitoring line

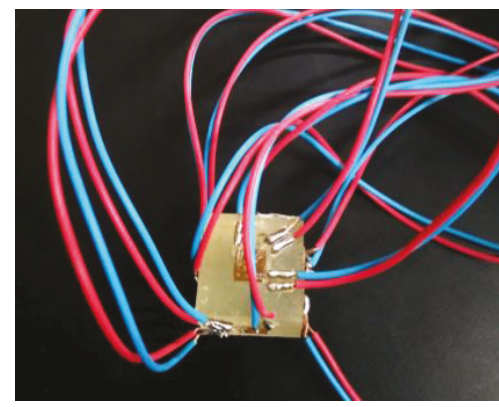

(b)

FIGURE 7: Schematic diagram of monitoring lines and strain sensor. (a) Stress monitoring lines. (b) Strain sensor.

TABLE 2: Similar material proportion of the model.

\begin{tabular}{lcccc}
\hline Lithology & Thickness $(\mathrm{cm})$ & Compressive strength $(\mathrm{MPa})$ & Actual density $\left(\mathrm{kg} / \mathrm{m}^{3}\right)$ & Proportion number \\
\hline Sandy mudstone & 7 & 21 & 2350 & 2430 \\
Coarse sandstone & 8 & 37 & 2550 & 355 \\
Fine sandstone & 7 & 36 & 2600 & 337 \\
Siltstone & 10 & 39 & 2300 & 328 \\
Medium sandstone & 14 & 27 & 2430 & 455 \\
Coarse sandstone & 7 & 37 & 2350 & 355 \\
Sandy mudstone & 4 & 21 & 2550 & 537 \\
Fine sandstone & 15 & 36 & 2600 & 337 \\
Siltstone & 8 & 39 & 2240 & 328 \\
Mudstone & 5 & 23 & 2550 & 437 \\
Fine sandstone & 8 & 36 & 2350 & 337 \\
Sandy mudstone & 4 & 21 & 1500 & 537 \\
Coal & 7 & 20 & 2600 & 573 \\
Siltstone & 16 & 39 & & 328 \\
\hline
\end{tabular}




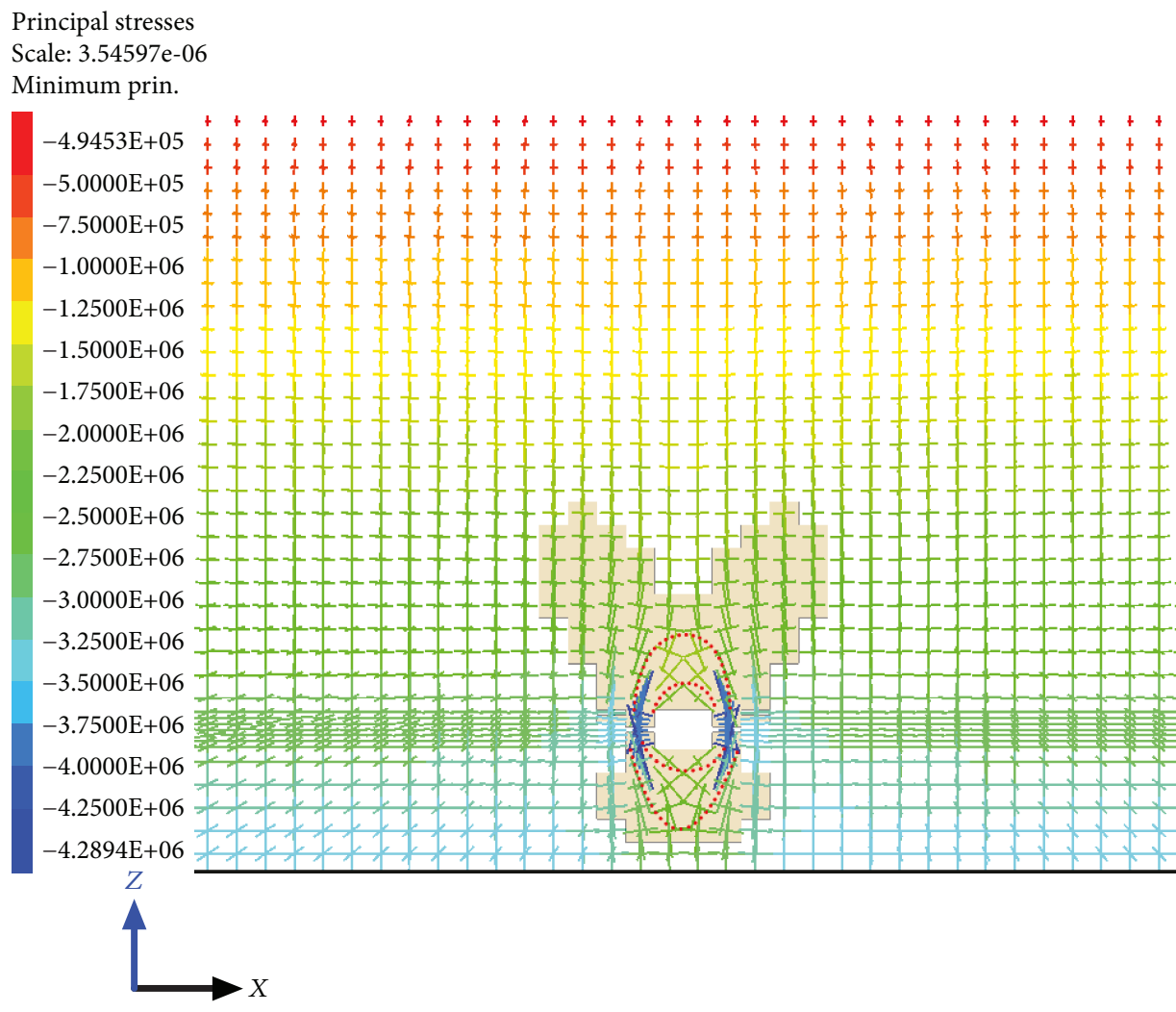

(a)
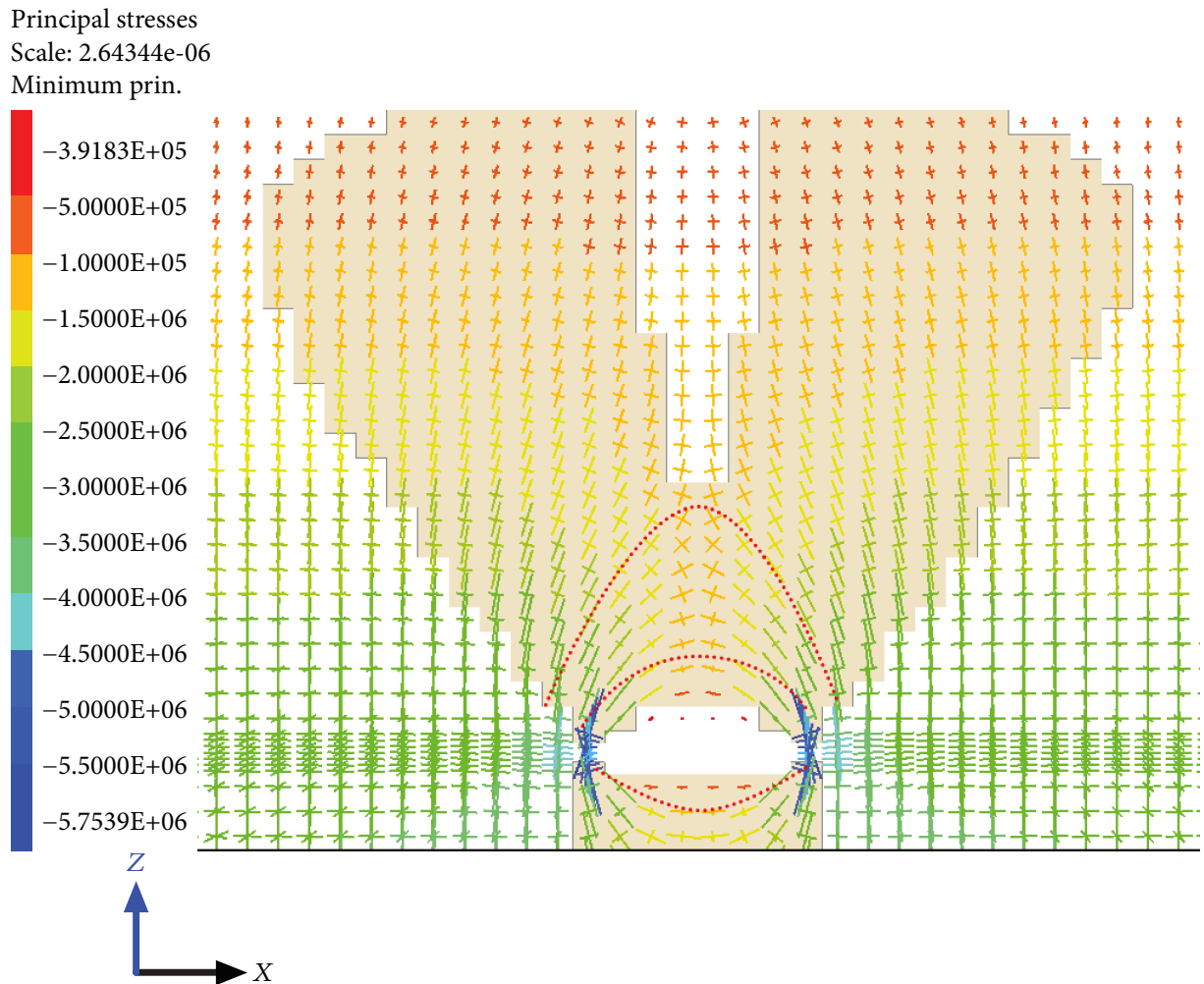

(b)

Figure 8: Continued. 


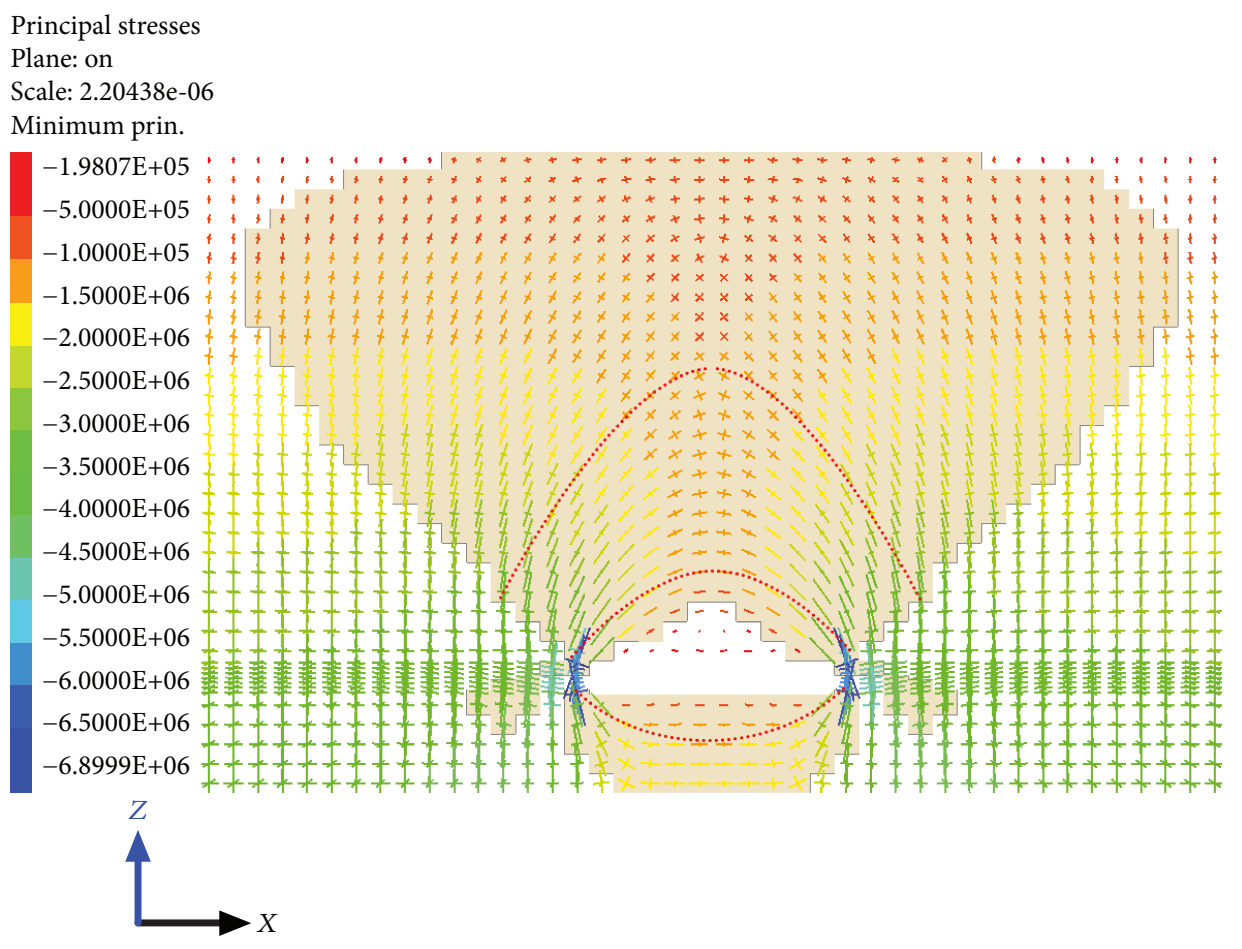

(c)

Figure 8: Vector field of the principal stress in the surrounding rock. (a) Initial mining stage. (b) The pressure arch in the near field. (c) The pressure arch in the far field.

mining disturbed zone was obviously deviated after the initial coal mining. As the shadow zone displayed the principal stress deviation, with the load of the hanging rock transferred to the surrounding rock at both sides of the goaf, the principal stress showed increasing.

As shown in Figure 8, with the working face advancing, the stress deviation zone expanded gradually. The direction of the principal stress in lower part of the principal stress deflection zone displayed horizontal, the compressive stress was deviated toward the surrounding rock of the mined-out area, assuming that the deflection zone of compressive stress above the mined-out area was the pressure arch area, and the pressure arch in the near field formed. Above the stress deflection zone was the in situ stress zone, and the pressure arch in the near field bore the upper rock load and transferred it to the stable surrounding rock. As the span of the goaf area increased, the whole direction of the principal stress of the upper overlying strata in the mining field deviated and the pressure arch in the far field formed.

As shown in Figure 9(a), selecting the top of the coal seam as the origin point, the vertical stress in midspan was analysed in the mining field. The principal stress of the overlying strata within $0-15 \mathrm{~m}$ above the coal seam deviated from the vertical direction after the initial mining stage, and the vertical stress of the deviation zone decreased. After the working face advancing $50 \mathrm{~m}$, the range of the principal stress and the horizontal stress in the deflection zone increased, and the vault of the pressure arch in the near field formed (Figure 9(b)).
After the working face advancing $100 \mathrm{~m}$, the unloading zone existed within $0-15 \mathrm{~m}$ in the midspan of the overlying strata below the pressure arch, where all the stress indicators of the overburden rock reduced. In the range of $10-55 \mathrm{~m}$, the maximum principal stress of the overburden rock was the horizontal stress, and the pressure arch situated in the horizontal stress zone increased. In addition, the pressure arch of the disturbed surrounding rock in the far field was in the range of 90-104 $\mathrm{m}$ (Figure 9(c)).

4.2. Characteristic Parameter Analysis of the Pressure Arch. After the horizontal principal stress of the midspan overburden rock exceeding the in situ stress, the pressure arch of the disturbed surrounding rock in the far field formed. As shown in Figure 10(a), taking the working face advancing $100 \mathrm{~m}$ as an example, the distribution of the arching index $k$ in the mining field was obtained by using built-in fish language programming in $\mathrm{FLAC}^{3 \mathrm{D}}$ software and the average $k_{\mathrm{c}}$ was 0.21 . The arching index of the roof strata in the near field was $k<0$, and the arching index of the upper hanging overburden rock and the undisturbed surrounding rock in both sides of the goaf was $k>0$. There was a symmetrical arching core in the pressure arch, where the arching index was greater than 0.21 . The arching index gradually decreased from the core area to the inner and outer boundary of the pressure arch, and the maximum value was located in the vault.

As shown in Figure 10(b), according to the arching index distribution characteristics of the pressure arch, the surrounding rock zone could be partitioned. There was the 


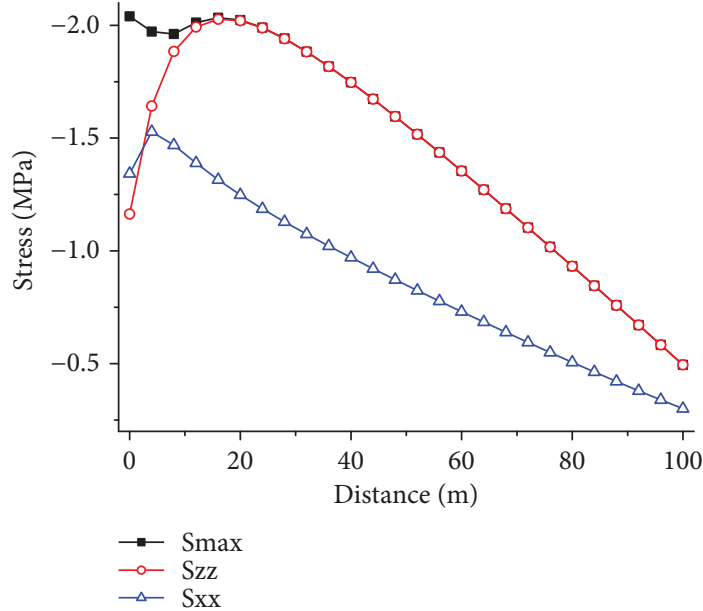

(a)

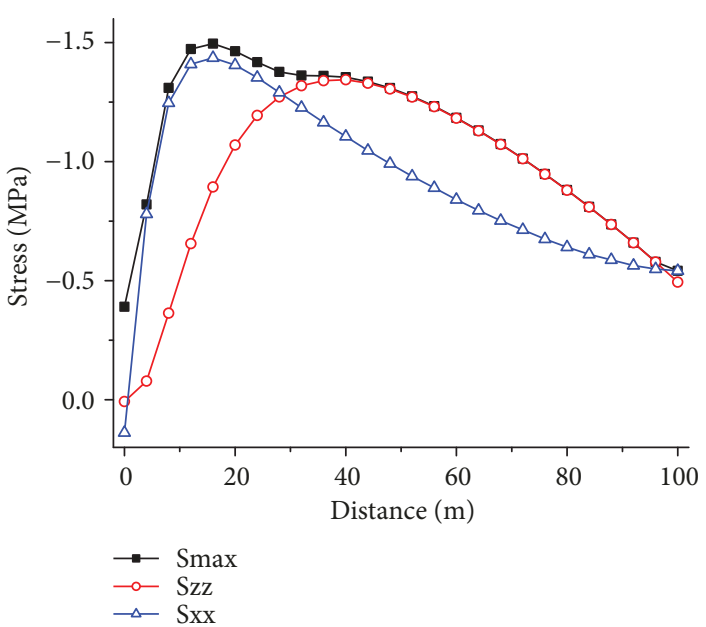

(b)

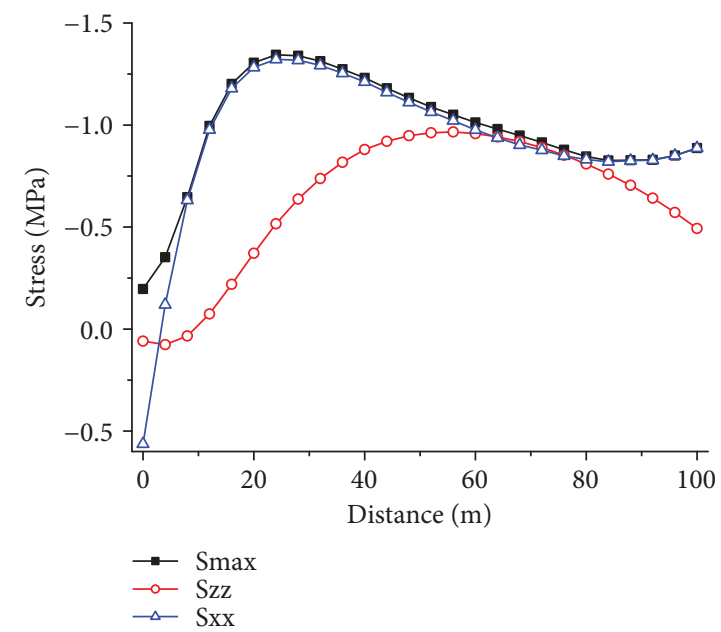

(c)

Figure 9: Stress distribution characteristics in the overlying strata. (a) Initial mining stage. (b) The pressure arch in the near field. (c) The pressure arch in the far field.

pressure arch in the disturbed surrounding rock, of which the arching core was near the goaf and which could bear high stress. The mining unloading zone was below the inner boundary of the pressure arch, and the caving zone was located at the bottom of the unloading zone.

To analyse the relationship between the bearing capacity of the pressure arch and the development of the caving zone, taking the middle position of the inclined direction of the working face as the research object, the width of the pressure arch core and the failure volume of the strata caused by coal mining were monitored. As shown in Figure 11, in the beginning of the pressure arch formation in the surrounding rock, the width of the pressure arch core continued to increase, which was kept constant after the pressure arch formation. When the width of the pressure arch core decreased, the failure volume of the strata caused by coal mining increased. The destructive volume of the rock strata displayed the nonuniform periodic variation as the working face advancing.

4.3. Relationships between Pressure Arch and Caving Arch. With the working face advancing $95 \mathrm{~m}$, the caving arch of the overburden broken zone in the near field was shown in Figure 12(a). The immediate roof and the basic roof showed the stepped structure. The marked red line was the squeezedarch structure by the rotation of the central broken blocks, and the upper abscission layer of the overlying strata was the symmetrical hinged structures.

As shown in Figure 12(b), the upper marked range was the macroscopic caving arch of the overburden broken zone, when the working face advanced $140 \mathrm{~m}$, an arch trace failure line developed along the inner boundary of the pressure arch for the concentrated stress and the caving arch was formed for the function of pressure arch in the bedrock. The lower marked line represented the squeezed-arch structure by the rotation of the broken blocks in the near field, which bore the load of the upper broken rocks. With the working face advancing $180 \mathrm{~m}$, as shown in Figure 12(c), the covering zone and the bending settlement zone of the overburden rock formed below the marked red line, the latter arch foot of the pressure arch of the broken rocks was situated in the compacted zone, and the front arch foot was located in the undisturbed overburden rocks above the coal wall. 
Index $\mathrm{K}$

Calculated by volumetric averaging
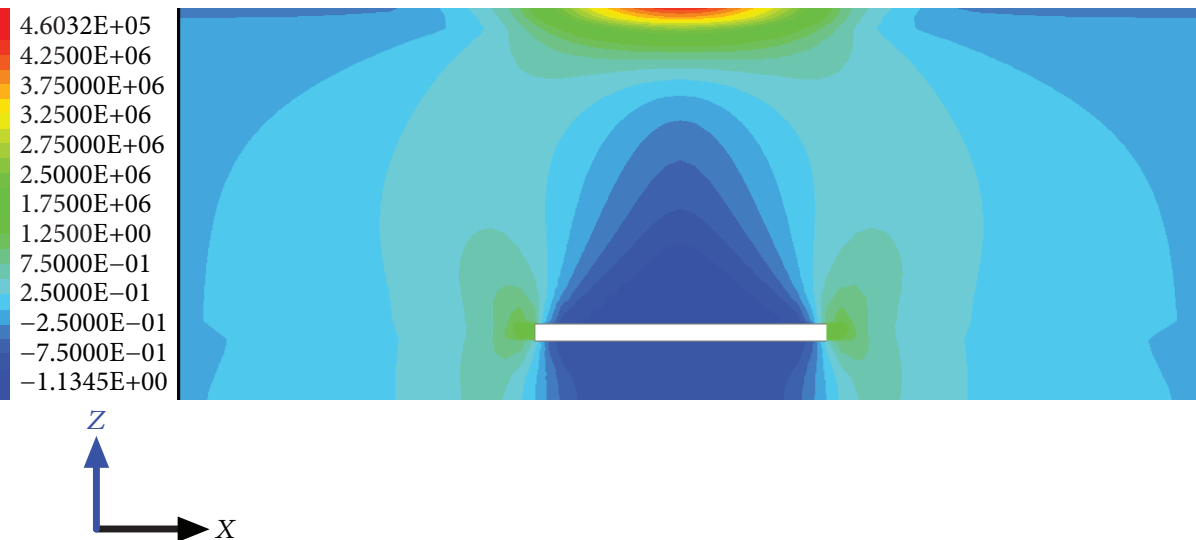

(a)

Zone

Color by group
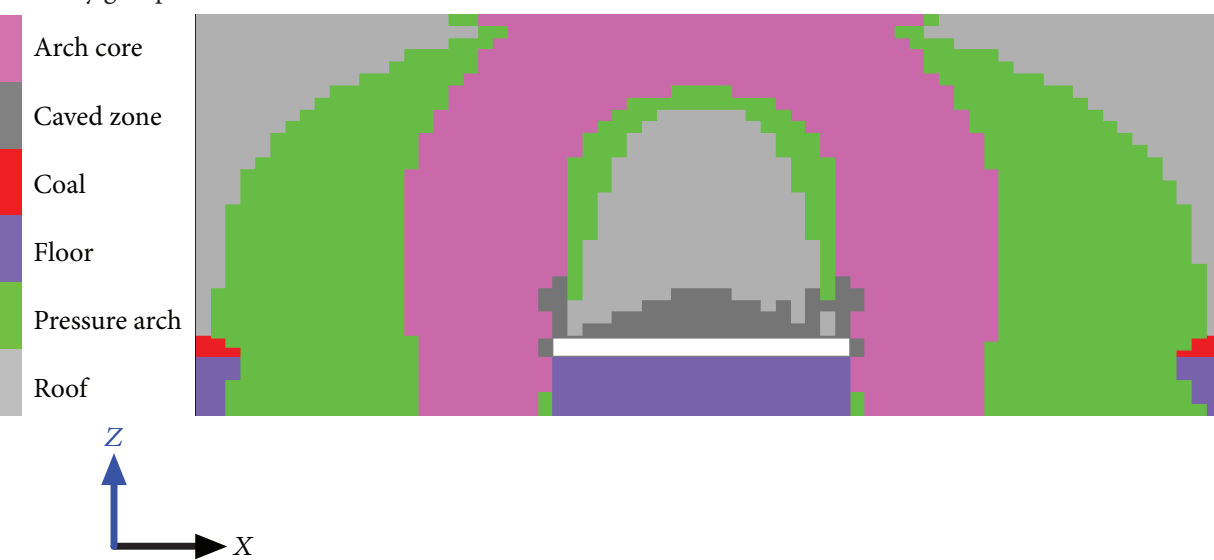

(b)

FIGURE 10: The arching index and pressure arch in the surrounding rock. (a) The arching index distribution. (b) The pressure arch in the surrounding rock.

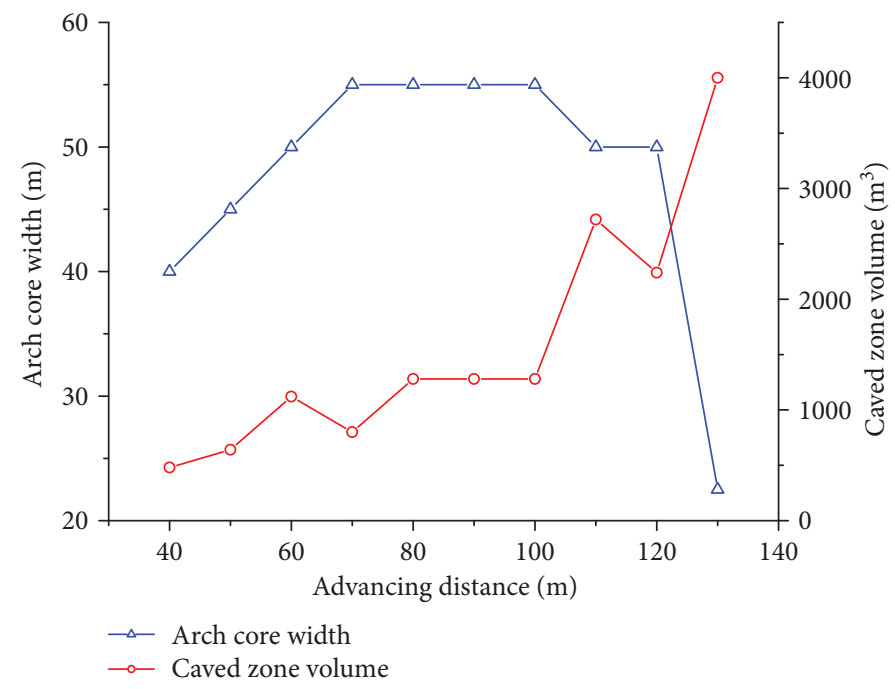

FIGURE 11: The width of the pressure arch core and failure volume of the strata caused by coal mining. 


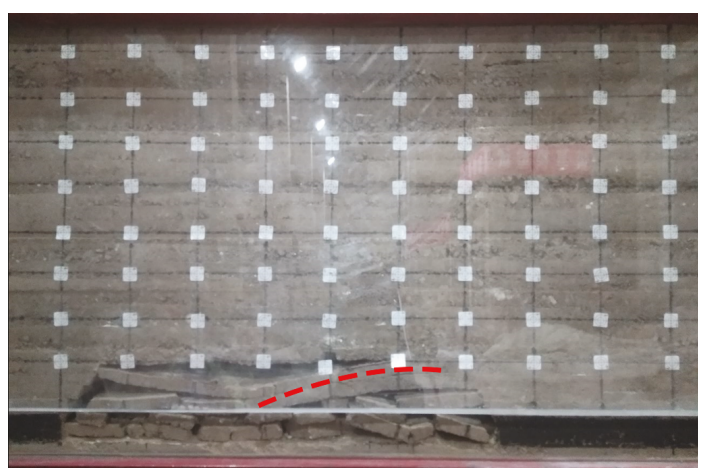

(a)

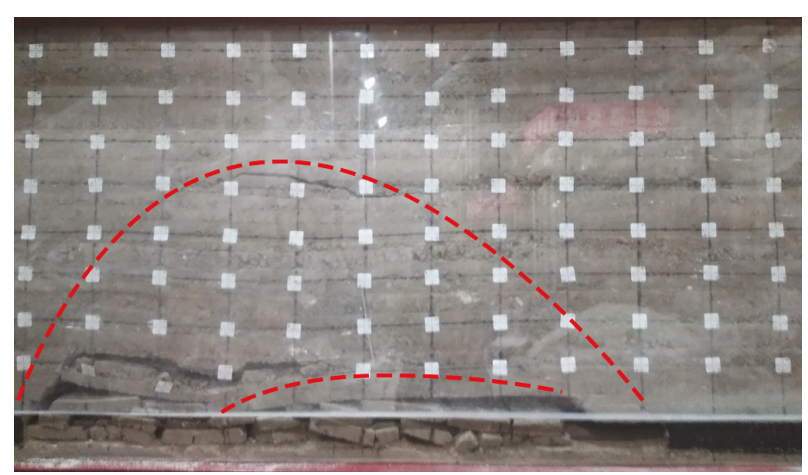

(b)

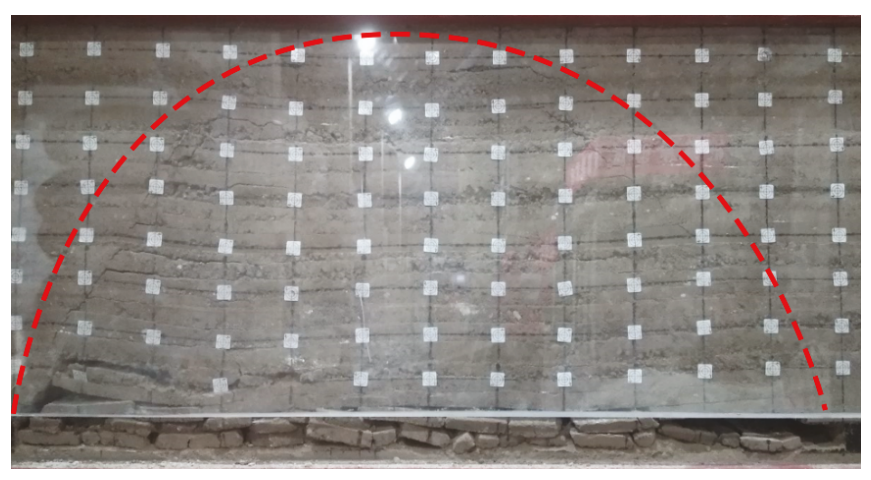

(c)

FIGURE 12: Evolution characteristics of the pressure arch and the caving zone. (a) The pressure arch in the near field. (b) The caving arch zone. (c) The inner boundary of the caving arch.

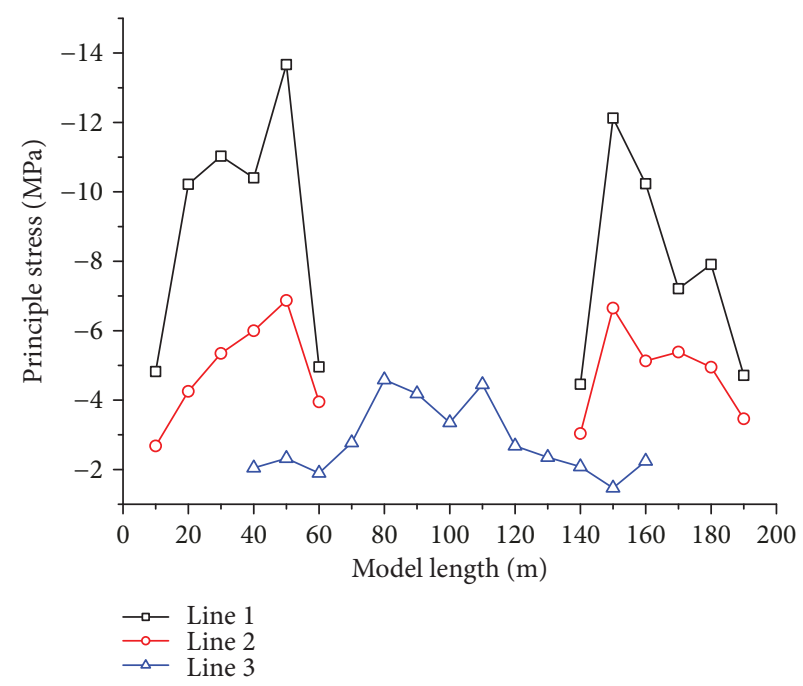

(a)

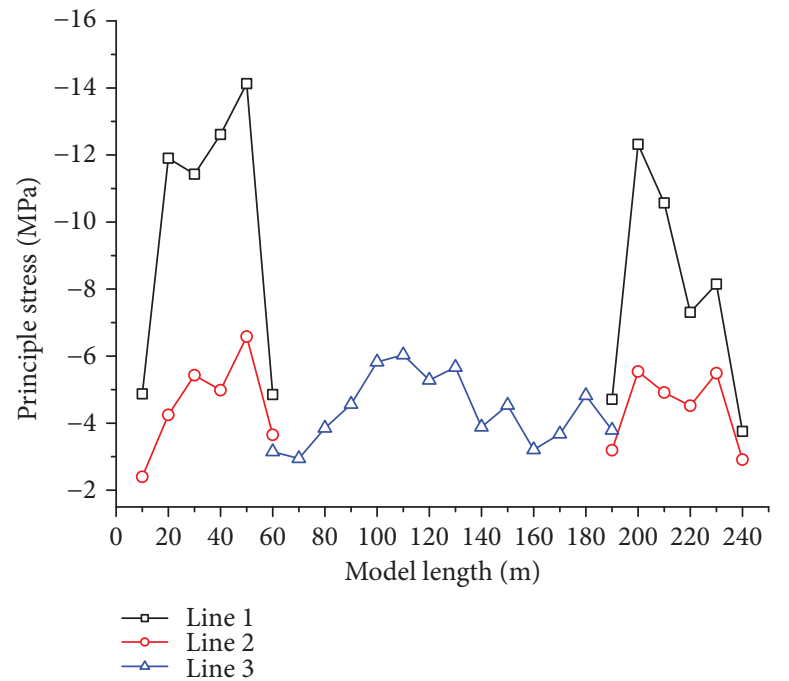

(b)

FIGURE 13: The distribution of the principle stress with the working face advancing in surrounding rock. (a) Advancing $90 \mathrm{~m}$. (b) Advancing $140 \mathrm{~m}$.

The distribution characteristics of the maximum principal stress of the broken strata in each monitoring line were shown in Figure 13(a) after the working face advancing $90 \mathrm{~m}$. The monitoring data showed that the zone of the increased principal stress formed the pressure arch in the surrounding rock. The arch foot was located in the lower rock strata in the near field, and the maximum principal stress of the arch foot was $13.67 \mathrm{MPa}$. The vault of the 
pressure arch was located in the upper hanging overburden rock in the far field, and the maximum principal stress of the vault was $4.59 \mathrm{MPa}$.

As shown in Figure 13(b), with the working face advancing $140 \mathrm{~m}$, the front arch foot of the pressure arch in the surrounding rock transferred to the undisturbed surrounding rock. Owing to the range of the hanging strata expanding, the load bored by the pressure arch increased, and the maximum principal stress of the arch foot arrived at $14.13 \mathrm{MPa}$. The vault of the pressure arch expanded simultaneously, and the maximum principal stress of the vault became 6.04 MPa.

The macroscopic pressure arch was the macro bearing structure of the overburden rock in the mining field, and the bearing capacity of different forms was diversity. The pressure arch size of the surrounding rock in the far field affected the range of the overburden broken zone in the near field [3,5]. The alternating instability of the caving zone led to the occurrence of the strong (weak) weighting periodically during shallow coal mining [4]. However, there was lack of mechanical criteria for the pressure arch size and bearing capacity, and the evolution relationship between the pressure arch and the caving zone failed to be established.

Since the coal mining disturbance made the principal stress in the upper hanging overburden rock deviate to the stable surrounding rock, the vault of the pressure arch formed in the zone of the increased horizontal principal stress in the midspan hanging overburden rock, and the arch shoulder and arch feet of the pressure arch were located in the undisturbed surrounding rock. There existed a core-bearing zone in the pressure arch which could be accurately delineated by the identification indicators of the pressure arch in the surrounding rock. The greater the width of the pressure arch core area was, the stronger the pressure arch bearing capacity was, and the destructive volume of the broken strata during coal mining displayed the nonuniform periodic variation with the working face advancing.

At the initial mining stage, the pressure arch in the near field formed in the overburden broken zone, and the weighting on the working face was relatively weak as a result of the small zone instability of the caving arch. After the macroscopic pressure arch formed, the bearing load of the support became larger, and the sliding instability of the caving arch would cause the strong weighting. The bearing capacity of the pressure arch in the surrounding rock affected the range of the caving zone. According to the width of the core area of the pressure arch, the bearing capacity of the overlying strata and the weight of the rock strata in the caving zone could be quantitatively analysed.

\section{Conclusions}

To analyse the evolution characteristics of the pressure arch during shallow coal mining, taking Shangwan mine in Shendong mining area as the engineering background, the mechanics model of the pressure arch in the mining field was built, and the mechanical indicators of the pressure arch and its load-bearing zone were put forward. Then, the mechanical model was verified and analysed, and the nonuniform weighting mechanism of the shallow coal seam with thick bedrock was revealed by analysing the evolution characteristics of the pressure arch and the caving zone. The conclusions were listed as follows:

(1) The increased zone of the horizontal principal stress in the midspan hanging overburden rock formed the vault of the pressure arch, and the arch feet and waist of the pressure arch were located in the surrounding rock. The formation of the pressure arch indicated that the load of overlying strata above mined-out area was effectively transferred to the surrounding rock; it is useful to evaluate the loadbearing area of the overlying strata. There existed a core-bearing zone in the pressure arch, and the arching indicators of the pressure arch were greater than the average value.

(2) The greater the width of the pressure arch core is, the stronger the pressure arch bearing capacity is. When the width of pressure arch core decreased, the failure volume of the strata caused by coal mining increased. The indexes of the pressure arch shape could be applied in area division of bedrock strata; the load carried by the working face support also could be calculated based on pressure arch area and failure area volume. The destructive volume of the rock strata displayed the nonuniform periodic variation as the working face advancing, so the roof weighting behaved as long/short weighting interval and strong/weak weighting strength, identifying the changing law of the pressure arch that provided a way to forecast roof weighting.

(3) At the initial mining stage, the broken blocks were the main bearing structure in the near field, the pressure arch effect occurred in the fractured roof strata when the broken blocks carried the load effectively, and the weighting on the working face was weak. The strong weighting of the working face was induced for the sliding instability of the caving arch, and the caving arch of the fractured bedrock was located under the inner boundary of the pressure arch. The latter arch foot of the pressure arch transferred to the compacted zone when the fractured bedrock was compacted in the mined-out area, and the front arch foot transferred to the stable surrounding rock in front of the coal wall; the fractured bedrock under the pressure arch was the load source of roof weighting.

Since the mining height, the length of the working face, and other factors have impacts on the pressure arch, the evolution characteristics of the pressure arch in the surrounding rock under different mining conditions needed to be further studied, and the formation conditions of the pressure arch under different lateral pressure coefficients are also the future research direction. 


\section{Data Availability}

The data used to support the findings of this study are available from the corresponding author upon request.

\section{Conflicts of Interest}

The authors declare that they have no conflicts of interest.

\section{Acknowledgments}

This work was financially supported by the National Natural Science Foundation of China (51774112, 51474188, and 51074140), the International Cooperation Project of Henan Science and Technology Department (182102410060), the Doctoral Fund of Henan Polytechnic University (B2015-67), the Research Fund of State and Local Joint Engineering Laboratory for Gas Drainage \& Ground Control of Deep Mines (Henan Polytechnic University) (G201614), and Taihang Scholars Program. All of these are gratefully appreciated.

\section{References}

[1] D. Zhang, G. Fan, L. Ma, and X. Wang, "Aquifer protection during longwall mining of shallow coal seams: a case study in the Shendong coalfield of China," International Journal of Coal Geology, vol. 86, no. 2-3, pp. 190-196, 2011.

[2] G. L. Hu, W. B. Zhu, and J. F. Ju, "Supports crushing types in the longwall mining of shallow seams," Journal of China Coal Society, vol. 39, no. 8, pp. 1625-1634, 2014.

[3] S. R. Wang, N. Li, C. L. Li, and C. Cao, "Distribution characteristics analysis of pressure-arch in horizontal stratified rocks under coal mining conditions," Tehnički Vjesnik-Technical Gazette, vol. 22, no. 4, pp. 997-1004, 2015.

[4] Y. F. Ren and Q. X. Qi, "Study on characteristic of stress field in surrounding rocks of shallow coalface under long wall mining," Journal of China Coal Society, vol. 36, no. 10, pp. 16121618, 2011.

[5] G. X. Xie, J. C. Chang, and K. Yang, "Investigations into stress shell characteristics of surrounding rock in fully mechanized top-coal caving face," International Journal of Rock Mechanics and Mining Sciences, vol. 46, no. 1, pp. 172-181, 2009.

[6] X. Cui, Y. Gao, and D. Yuan, "Sudden surface collapse disasters caused by shallow partial mining in Datong coalfield, China," Natural Hazards, vol. 74, no. 2, pp. 911-929, 2014.

[7] S. Wang, N. Li, C. Li, Z. Zou, and X. Chang, "Instability mechanism analysis of pressure-arch in coal mining field under different seam dip angles," DYNA Ingeniería e Industria, vol. 90, no. 3, pp. 279-284, 2015.

[8] J. Ju and J. Xu, "Structural characteristics of key strata and strata behaviour of a fully mechanized longwall face with 7.0 $\mathrm{m}$ height chocks," International Journal of Rock Mechanics and Mining Sciences, vol. 58, no. 1, pp. 46-54, 2013.

[9] Q. X. Huang, B. Dong, and S. S. Chen, "Determination of roof pressure law and support resistance in the mining face with super-large mining height in approximate shallow coal seam," Journal of Mining \& Safety Engineering, vol. 32, no. 4, pp. 175$181,2016$.

[10] X. Liu, G. Song, and X. Li, "Classification of roof strata and calculation of powered support loads in shallow coal seams of
China," Journal of the Southern African Institute of Mining and Metallurgy, vol. 115, no. 11, pp. 1113-1119, 2015.

[11] A. K. Soni, K. K. K. Singh, A. Prakash, K. B. Singh, and A. K. Chakraboraty, "Shallow cover over coal mining: a case study of subsidence at Kamptee Colliery, Nagpur, India," Bulletin of Engineering Geology and the Environment, vol. 66, no. 3, pp. 311-318, 2007.

[12] P. R. Helm, C. T. Davie, and S. Glendinning, "Numerical modelling of shallow abandoned mine working subsidence affecting transport infrastructure," Engineering Geology, vol. 154, pp. 6-19, 2013.

[13] E. F. Salmi, M. Nazem, and M. Karakus, "The effect of rock mass gradual deterioration on the mechanism of post-mining subsidence over shallow abandoned coal mines," International Journal of Rock Mechanics and Mining Sciences, vol. 91, pp. 59-71, 2017.

[14] L. He and Q. B. Zhang, "Numerical investigation of arching mechanism to underground excavation in jointed rock mass," Tunnelling and Underground Space Technology, vol. 50, pp. 54-67, 2015.

[15] Y. Wang, H. Jing, Q. Zhang, N. Luo, and X. Yin, "Prediction of collapse scope of deep-buried tunnels using pressure arch theory," Mathematical Problems in Engineering, vol. 2016, Article ID 2628174, 10 pages, 2016.

[16] X. X. Kong, Q. S. Liu, Q. B. Zhang, Y. X. Wu, and J. Zhao, "A method to estimate the pressure arch formation above underground excavation in rock mass," Tunnelling and Underground Space Technology, vol. 71, pp. 382-390, 2018.

[17] Q. S. Bai, S. H. Tu, C. Zhang, and D. Zhu, "Discrete element modeling of progressive failure in a wide coal roadway from water-rich roofs," International Journal of Coal Geology, vol. 167, pp. 215-229, 2016.

[18] S. R. Wang, X. L. Liu, Z. S. Zou et al., "A combined multifunctional experimental platform under servo control loading conditions," China Patent 201620230001.X, November 2016. 

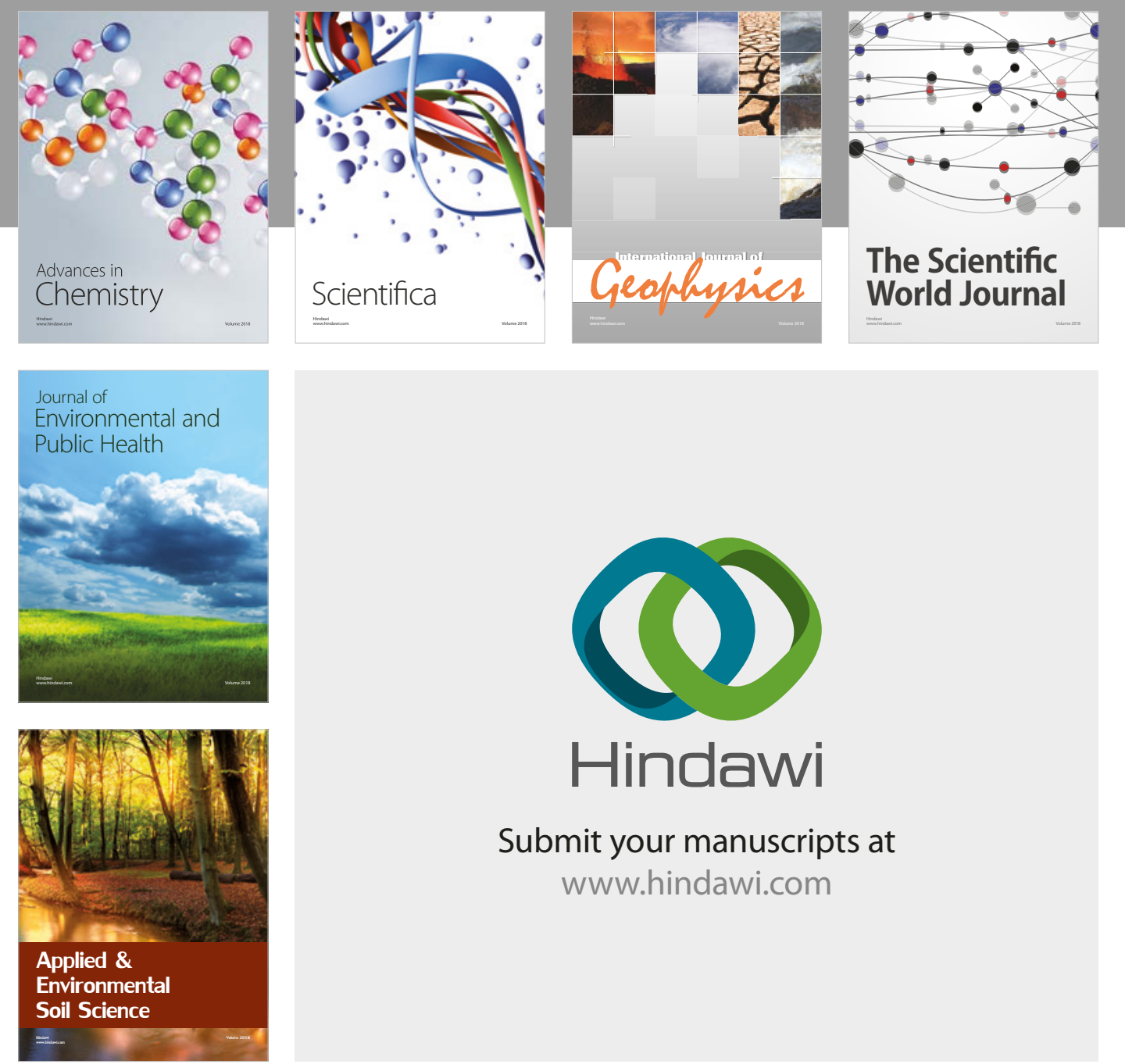

The Scientific

\section{World Journal}
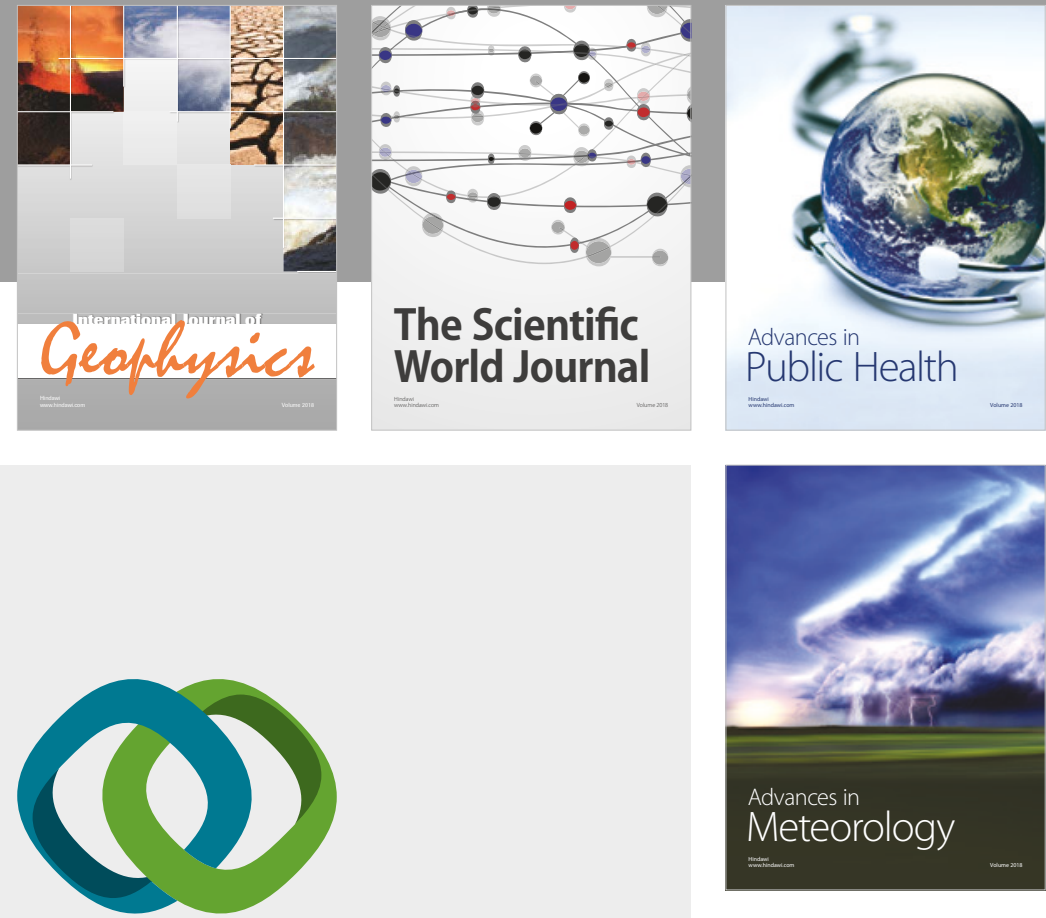

Advan

Public Health

\section{Hindawi}

Submit your manuscripts at

www.hindawi.com
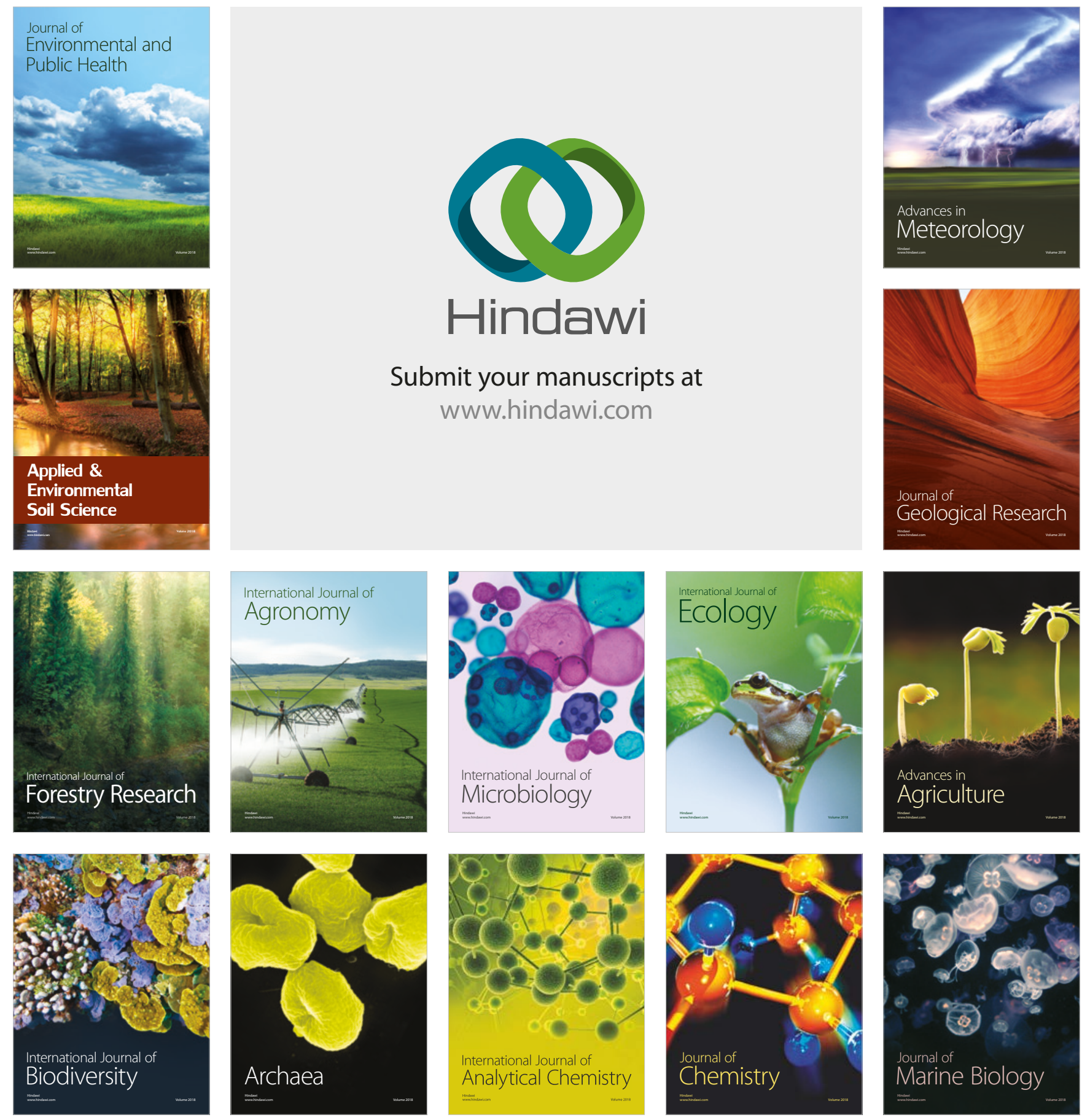